\title{
Введение
}

Когда речь идет о переводе, то возникает некоторое неискоренимое проблематичное напряжение, касающееся норм и критериев, обеспечивающих процесс перевода. Мы полагаем, что перевод согласно собственному понятийному статусу может обладать, одновременно, теоретическими и техническими характеристиками, и если технические аспекты перевода так или иначе структурны и формальны, благодаря чему перевод обретает видимые очертания и устойчивые конструкты оригинала, - так называемое стремление к «точности», то теоретические аспекты перевода, охватывая попеременно семантические, фразеологические, текстовые или контекстуальные ансамбли, утверждает возрастающую степень вариативности и релевантной произвольности перевода, - так называемое стремление к «свободе». Это вовсе не означает, что теоретические нормы и положения, обеспечивающие процесс перевода, не могут быть нацелены на «точность», но ведь настоятельно необходимо прояснить содержание понятий «точность» и «свобода» перевода, чтобы выявить способ и характер их отношений. Но может статься и так, что отношения между этими фундаментальными постулатами носят более первичный характер; именно способ и тип отношения определяет емкость и содержательность понятия, - будь то оппозиция или взаимодополнительность, как отношение рода и вида или диалектического взаимоперехода, мимезиса или техник memoria. Все эти отношения удерживают некоторые моменты различий, которые стремятся быть преодоленными; вот почему перевод неизменно сохраняет свою преходящесть и некоторую непреодолимую проблематичность. Отношение между оригиналом и переводом остается наиболее драматическим сюжетом европейской культуры, которое охватывает почти все области человеческой мысли и деятельности (коммуникация, традиция, история, наука). Но, по всей видимости, нет никаких оснований размыкать эти сферы в целях технической спецификации моментов перевода, с другой стороны, существует более или менее разработанная версия о формах перевода в строго языковых пределах. Комментированный пересказ эссе Якобсона «О переводе» (1959 г.), который осуществляет Ж.Деррида в своей статье «Вокруг Вавилонских башен», как нельзя, кстати, объемлет типологическую разноуровневость моментов перевода. «Перевод внутриязыковой интерпретирует лингвистические знаки при помощи других знаков того же языка.... Далее, возможно то, что Якобсон изящно называет переводом «собственно говоря», перевод межъязыковой, который интерпретирует лингвистические знаки при помощи другого языка, что вызывает те же предположения, как и в случае внутриязыкового перевода. Возможен, наконец, и межсемиотический перевод или трансмутация, который интерпретирует лингвистические знаки при помощи системы знаков нелингвистических.» (Комментарии 1997; 89). Следует также отметить, что связь между философией и проблематикой перевода настолько непосредственна, насколько философия реализовывалась в языковой форме. Не столько язык, как сложившаяся фактура, но способ присутствия в языке или даже отсутствия составляло универсальную философскую заботу.

\section{Часть первая}

Существуют универсальные символические контексты, которые определяют способы оценки и анализа явлений общего культурного значения. Одним из таких символических сюжетов является мифопоэтический образ пещеры, описанный в седьмой книге диалога Платона «Государство». Соотношение оригинал - копия составляет основной сюжет вышеуказанной книги и любопытным образом формирует концепцию переводимости. Конструкция платоновской пещеры насыщенна эвристична. Рассмотрим эту диспозицию:

«Представь, что люди как бы находятся в подземном жилище наподобие пещеры, где во всю ее длину тянется широкий просвет. С малых лет у них на ногах и на шее оковы, так что людям не двинуться с места, и видят они только то, что у них прямо перед глазами, ибо повернуть голову они не могут из-за этих оков. Люди обращены спиной к свету, исходящему от огня, который горит далеко в вышине, а между огнем и узниками проходит 
верхняя дорога, огражденная, представь, невысокой стеной вроде той ширмы, за которой фокусники помещают своих помощников, когда поверх ширмы показывают кукол.... Так представь же себе и то, что за этой стеной другие люди несут различную утварь, держа ее так, что она видна поверх стены; проносят они и статуи, и всяческие изображения живых существ, сделанные из камня и дерева, при этом, как водится, одни из несущих разговаривают, другие молчат....Прежде всего, разве ты думаешь, что, находясь в таком положении, люди что-нибудь видят, свое ли или чужое, кроме теней, отбрасываемых огнем на расположенную перед ними стену пещеры?» (Платон 1972: 295).

Известно, что Платон в своих диалогах многократно концептуализирует символический образ пещеры, прописывая интеллигибельный мир умопостигаемых идей. Но он менее детально прорабатывает способы отношения истинно-сущих эйдосов и преходящих сущностей, указывая лишь на подражательный (мимезис) характер бытия видимых объектов мира. Этот негативный аспект подражания будет распространяться и на естественные физические объекты и на объекты-вещи, полученные в результате применения навыков и techne, то есть вся область поэзиса или созидания будет однозначно негативным бытием с минимальным качеством присутствия. Однако вернемся еще раз к вышеописанной структуре пещеры и рассмотрим способ переводимости. Прежде всего, вещи, которые проносятся вдоль стены-ширмы, непроницаемы, они содержательно насыщены и имеют устойчивую и завершенную форму. Источник света расположен где-то далеко и высоко. Свет не может пронзить эти вещи, но, обтекая по поверхности плотной материальности вещи, проецирует на стену пещеры очертания и форму вещи, которая становится возможной как игра света и тени. Именно содержание вещи образует тень, а свет, соприкасаясь с границей тени, вырисовывает форму вещи на стене пещеры. Свет переносит форму вещи, оставляя пустой и темной содержание вещи. Мимезис, как принцип перевода самотождественных и истинных в себе сущностей в область видимостей и множественности, должен по необходимости утверждать негацию, - отрицание этих видимостей. Различие между подлинником и видимостью противоречивое: утверждать видимость как момент ее же отрицания. Это различие описывается не столько как аналогия или подобие, сколько складывается в форме оппозиции. Следовательно, мимезис в целом это нисходящее действие высшего "огня" или блага, не присущее какому-либо сущему. Благо есть нечто, что превосходит любое сущее, тождественное, истинное, и в своем нисхождении использует мимезис, устанавливая неотменяемую иерархию подлинник копия.

Этот негативный аспект нисходящего блага, доверенный мимезису, Платон компенсирует утвердительной стратегией восходящего блага, которая формируется в сфере «воспоминания». «Когда душа сама по себе, без участия тела, наилучшим образом воспроизводит то, что она испытала когда-то совместно с телом, мы говорим, что она вспоминает... Равным образом, когда душа, утратив память об ощущении или о знании, снова вызовет ее в самой себе, то все это мы называем воспоминаниями». (Платон 1972: 35).

Воспоминание Платон всегда мыслит как возвращение или восхождение души, как поворот и встречу, и тем самым отличает его от памяти, как некоторый вид ощущений. Агональный оттенок всей философии Платона, особый драматический характер его концепций, формируют достаточно очевидную связь между воспоминанием и подражанием. «Единственная проблема, проходящая через всю философию Платона и определяющая классификацию наук и искусств, это вечное соизмерение соперников, отбор претендентов, различение вещи и ее симулякров в недрах псевдо-рода или крупного вида. Речь идет о проведении различия, - то есть о действиях в глубинах непосредственного, о диалектике непосредственного, опасном испытании без путеводной нити и без сетки. Ведь согласно античному обычаю, обычаю мифа или эпопеи, ложные претенденты должны умереть».

(Деле 1998: 84). 
В случае мимезиса работает соотношение подлинник-подобие, и максимальная интенсивность данного соотношения предполагает «точность» как момент взаимообратимости, тогда как воспоминание выражает отношение новизны, неповторимости (как это не парадоксально) как момент только здесь и сейчас представленной истины. Так как воспоминание вовсе не полагает акт непосредственного переживания события, но некоторое воспоминающееся качество события, что всегда единственно и ново. Мимезис - это различие по принципу отрицания. Воспоминание - это различие по принципу утверждения. Пересечение этих принципов, которое возможно в некотором интенциональном промежутке, образованном между оригиналом и копией, знаменует особую интенсивность проявления «Блага».

Силы восхождения и нисхождения образуют мимолетное и неустойчивое равенство между копией-переводом и оригиналом. «Свет» и «тень» являются фазами различия. Свет может быть оттенен, и в этом смысле начать быть; тень может быть освещена, и в этом смысле стать самим светом. Также и действие содержит в себе свою причину, являясь, одновременно, причиной для другого действия. А значит, перевод-копия - это не только последний, завершенный результат, но то, что продвигает благо или смысл к новым выразительным возможностям. Такая взаимообратимая двойственность присуща мифу, который всегда находится в движении, в то же время, оставаясь неподвижной. Миф - как пересказ события, как перевод оригинального, изначального, божественного смысла в форму философской демонстрации, поучения и, наконец, концептуализации. И миф - как перевод видимостей в язык концептуальной (эпистемической) философии, в язык истинных, подлинных сущностей. Таким образом, миф то противостоит мышлению или диалектике, то обосновывает основоположения в качестве элемента диалектики. И если мимезис противопоставляет мышление и миф, утверждая мышление в качестве единичности и оригинала, а миф как сферу множественных копий, то воспоминание использует многое или сферу копий как основу их возможного диалектического преобразования в единичность. Благо не может быть оправдано господством исключительно мимезиса. А воспоминание невозможно в сфере единичного. По всей видимости, Платон допускает некое движение оригинала и копии, которое устанавливает своеобразный паритет и равенство между ними, но всегда будет сохраняться неотменяемое различие; копия стремится не только к оригиналу, но ко всем остальным копиям, тогда как оригинал всегда однонаправлен.

Вот некоторые следствия, которые очевидным образом вытекают из подобных концептуальных конструкций, и формируют смысловой и ценностный фон теорий перевода. Оригинальный текст как цельность содержания и выражения сохраняет своеобразный интенциональный зазор между ними, взывая к неизменности содержания и вариативности выражения. Смысл остается одним и тем же, а знак блуждает по языкам в поисках собственного двойника. Найдя этот иной знак, он доверяет ему смысл, который, должно быть, сохраняет свое безразличие. С другой стороны, учитывая неотменяемую дистанцию между интенцией записывания и ставшим письмом, переводчик распределяет и помещает свое внимание на характер и структуру этого зазора, на то, как происходит взаимодействие между замысливанием, осуществлением и осуществленным. Зазор между замыслом и текстом позволяет переводчику допустить некоторый другой текст, на другом языке, который мог быть результатом этойнеустранимой дистанции, тех сложных фигур интенциональностей, которые продуцируют множественности, но реализуются в одном из единичностей. Текст - это всегда актуальность многих иных возможных текстов.

Однако античное понимание мимезиса вовсе не исчерпывается платоновской интерпретацией, где миф распределяет ценности по нисходящей и восходящей траектории, где подражание и воспоминание создают круговращение идей, которые, в свою очередь, создают исключительно платоновскую мифопоэтическую диалектику, и, в целом, философию. Мимезис получает совершенно иное измерение в «Поэтике» Аристотеля, и его характеристики подражания несколько смещают оценки процедур переводимости.

\section{Часть в торая.}


Аристотелевская концепция мимезиса разворачивается в пространстве мифа, но миф более не представляется в качестве элемента диалектики. Миф рассматривается как самостоятельная инстанция и имеет свою четкую структуру. Иными словами, миф есть фабула, где подражание раскрывает свою структуру, методологию и предметную ориентацию:

«Подражание действию есть фабула; под этой фабулой я разумею сочетание фактов, под характерами то, почему действующих лиц мы называем какими-нибудь, а под мыслю то, что говорящие доказывают что-либо или просто высказывают свое мнение. Итак, необходимо, чтобы в каждой трагедии было шесть частей... Части эти суть: фабула, характеры, разумность, сценическая обстановка, словесное выражение и музыкальная композиция. К средствам подражания относятся две части, к способу - одна, и к предмету три...» (Аристотель 1957: 58).

Подражание приобретает у Аристотеля некоторое первичное качество, которое способно нечто произвести, быть продуктивным, позитивным и активным принципом. Подражание формируется в естественной среде человеческого существования. «Как кажется, поэтическое искусство породили вообще две и притоместественные причины. Вопервых, подражание присуще людям с детства, и они тем отличаются от других животных, что наиболее способны к подражанию, благодаря которому приобретают и первые знания; а во-вторых, продукты подражания всем доставляют удовольствие.» (Аристотель 1957: 48).

Мимезис начинает вбирать в себя, составлять собственный смысл из знания и удовольствия, иными словами, именно мимезис делает знание и удовольствие способом конституирования и самосозидания человека. Аристотель в дальнейшем прописывает некоторые качества этого удовольствия, которые суть трагическое очищение (catharsis), сострадание, страх. Мимезис как бы позволяет перевести произведение искусства, и не только, из сферы представленного, репрезентированного в область непосредственного переживания, в некоторый целостный опыт человеческого бытия. Но для такого перевода необходимо особая технология, навык, комплекс различных подражательных праксисов. «Подражание происходит в ритме, слове и гармонии, отдельно или вместе.... Но есть некоторые искусства, которые пользуются всем сказанным, - то есть ритмом, мелодией и метром; такова, например дифирамбическая поэзия, номы (гимны под аккомпанемент кифары), трагедия и комедия; различаются же они тем, что одни пользуются всем этим сразу, а другие в отдельных своих частях.» (Аристотель 1957: 40-42). Исходя из собственного techne подражание также различно, подобно тому, как и в собственной стихии оно различается на удовольствие и знание: «Подражательные искусства различаются в трех отношениях: или тем, в чем совершается подражание, или тем, чему подражают, или тем, как подражают.» (Аристотель 1957: 40).

Аристотель также указывает на то, что подражатель должен исключать себя из процедур подражания и не смешивать природу подражания и техники подражания. Это различие позволяет поэту достигать эффектов «узнавания», которые и позволят осуществиться трагическому очищению. Воспоминание является одним из видов узнавания. Первое - это узнавание «посредством внешних признаков»; далее узнавание осуществляется как придумывание; «...третье есть узнавание посредством воспоминания, когда кто-либо, при виде чего-нибудь, испытывает сильное волнение.» (Аристотель 1957: 592); и четвертый вид узнавания происходит вследствие умозаключения. Но представляется, что наиболее интересный аспект, затрагивающий соотношение поэт произведение, разворачивается в какой-то особой области бессмыслицы (a'topoi). Аристотель фактически говорит о превосходстве произведения или копии над оригиналом или образцом: «...надо предпочесть лучше это невозможное, так как следует превосходить образец.» (Аристотель 1957: 133). Последуем за рассуждениями Аристотеля, чтобы не упустить каких либо деталей, которые подводят к данному выводу. «Так как поэт есть подражатель, подобно живописцу или какому-нибудь другому художнику, то необходимо 
ему подражать непременно чему-нибудь одному из трех: или он должен изображать вещи так, как они были и есть, или как о них говорят или думают, или какими они должны быть.... Но если поэт уже сложил ... фабулу и она кажется ему более вероятной, то можно допустить и бессмыслицу.... Вообще при суждении о невозможном в поэзии следует обращать внимание на идеализацию или ходячее представление о вещах; именно в поэтическом произведении предпочтительнее вероятное невозможное, чем невероятное, хотя и возможное....» (Аристотель 1957: 125;127;132-133).

Надо иметь в виду, что Аристотель не раз указывает (в «Метафизике», «Вторая Аналитика») на способ существования единичных объектов. Общее осуществляется только

в единичном, поэтому поэзия, будучи знанием общего, создает неповторимые и единичные образцы, тогда как непосредственно общее не может быть реализовано; вот почему философия не миметична, а значит, не переводима. Если мимезис и поэзис составляют одинаковый праксис, выраженный в творчестве и созидании, то соотношение оригинала и копии, образца и произведения также полагает равенство, но во многих случаях и превосходство последнего. Последующая греко-македонская экспансия будет утверждать превосходство греческой семантической и лингвистической среды, и произведения других культур будут легитимироваться посредством перевода на греческий язык. Наиболее очевидным образом эта тенденция выявляется на примере перевода ветхозаветных книг; так называемая история Септуагинты - перевода семидесяти. Первоначальный восторг иудейских первосвященников уже во втором веке н.э. сменился радикальным отказом от перевода. Но эта тема предполагает несколько иной акцент изложения, поэтому мы до времени отложим это рассмотрение.

\section{Часть третья.}

По-видимому, проблема перевода как такового в собственной лексической и семантической определенности - достаточно сложная задача; перевод пребывает всегда в некотором ускользающем, рассредоточенном пространстве, ведь перевод как бы предшествует языку, но и следует за языком. Амбивалентный характер перевода вынуждает говорить и о практике перевода, и о смысле перевода как бы одновременно. Можно полагаться на романтическое допущение о родстве всех языков, и, следовательно, на возможность финальной тождественности смысловых полей языков, но это допущение слишком произвольно. Достаточно сказать, что маршрут, траектория, скорость движения к смыслу довольно различен в языках, но помимо этого, существуют так называемые непереводимые остатки, и еще, в самой ткани языка вплетены неязыковые явления. «...Отметим одно из ограничений теорий перевода: они слишком часто трактуют переход от одного языка к другому и не рассматривают в достаточной степени возможность вовлечения

в один и тот же текст более чем двух языков. Как перевести текст, написанный на двух языках сразу? Как "передать" эффект множественности? А если переводишь, пользуясь сразу несколькими языками, будет ли это все еще называться переводом?» (Комментарии 1997: 87). Далее Деррида обращается к непереводимым словесным формам: «Ведь имя собственное как таковое всегда остается непереводимым; факт, исходя из которого, можно заключить, что оно, строго говоря, не принадлежит языку, системе языка, все равно переводимого или переводящего, на том же основании, что и другие слова.» (Комментарии 1997: 87).

Но обратимся к наиболее значительной работе Вальтера Беньямина, где он весьма парадоксально формирует смысл перевода, и задает универсальную концептуальную мотивировку актам перевода. Прежде всего, то, что мы называем оригинальным произведением вовсе не ориентировано на потребителя, получателя, адресата, и, следовательно, не полагает никакого перевода. Оригинал - это то, что мыслит себя завершенным: «Ни одно стихотворение не предназначено читателю, ни одна картина зрителю, ни одна симфония слушателю.» (Комментарии 1997: 65). Если мы полагаем, 
считает Беньямин, что оригинал может обосновать свое бытие вне восприятия, чтения, вне каких-то коммуникативных порядков (оригинал ничего не сообщает, так как сообщение есть несущественное в произведении), то и перевод должен будет удерживать эти характеристики. Вопросы, на которые Беньямин пытается ответить, достаточно радикальны. «Предназначен ли перевод читателям, не понимающим оригинала?... Если же оригинал существует не ради читателя, то как в таком случае следует понимать перевод? Перевод есть форма. Рассматривая его как таковую, мы необходимо возвращаемся к оригиналу. В нем заключен управляющий переводом закон: переводимость. Вопрос о переводимости оригинала имеет двоякий смыл. Он может означать: найдется ли во всей совокупности читателей произведения адекватный переводчик? Или же, более непосредственно, допускает ли оно по своей сути перевод, и тем самым - в соответствии со значимостью этой формы - требует ли оно его?» (Комментарии 1997: 65-66).

Деррида отследил логику этого вопрошания, радикализируя возможные последствия: «Ибо если структура оригинала помечена требованием быть переведенным, то, именно возводя это в закон, и сам оригинал тоже начинает с залезания в долг по отношению к переводчику. Оригинал первый должник, первый проситель, он начинает с нехватки и вымаливания перевода.» (Комментарии 1997: 98).

Беньямин пытается отстраниться от сложившихся форм понимания перевода. Он пытается отвести смысл перевода, понимание значения перевода от традиционных теорий имитации или мимезиса с одной стороны, но также заново переопределить филологическую теорию родства языков. Считается, что перевод обосновывает родство между языками, так как всякое родство предполагает схожесть. Однако сходимость языков вовсе не доказывает, что языки произошли из предполагаемого единого источника. Бесспорно, языки демонстрируют вневременную, априорную схожесть, но эта схожесть проявляется в желании выразиться, и, следовательно, мы можем говорить о существовании в каком-то виртуальном пространстве между языками своеобразного истинного языка или "чистого" языка. Но пребывать в этом пространстве обычные языки не в состоянии, однако стремиться к этому является основной задачей перевода и переводчика. «А пока этого не произойдет, оно по-прежнему будет скрыто в языке....Говоря это, мы тем самым, разумеется, признаем, что всякий перевод - всего лишь некое предварительное средство преодоления чуждости языков друг другу. Иное разрешение этой чуждости - не временное и предварительное, но мгновенное и окончательное - остается вне досягаемости человека; по крайней мере, оно не доступно напрямую.» (Комментарии 1997: 70).

Итак, достижение выразительных средств чистого или истинного языка непосредственно связано с переводом. Оригинальное произведение укоренено в ткани собственного языка, содержание и язык тесно переплетены между собой, составляют единое целое, тогда как перевод вырывает содержание из языковой среды, в которой это содержание было создано, и переносит его в область собственного языка. Но разве возможен такой механический разрыв и перенос? Никакого отдельного содержания или сообщения, без того, чтобы не захватить и весь язык в целом, перевод не в состоянии осуществить. При переводе происходит некая универсальная интеграция языков; сам перевод (хороший перевод) есть воплощение, точнее, осуществление этого единения. Перевод всегда осуществляется на уровне языка в целом, но не на уровне отдельных высказываний, или строго смысловых описаний. «... При этом сами языки гармонируют в нем друг с другом, взаимно дополняя и примиряя свои способы производства значения. Иначе говоря, если существует язык истины, который в тишине и спокойствии хранит все высшие тайны, над раскрытием которых бьется человеческая мысль, то этот язык истины истинный язык. И именно он - язык, в предсказании и описании которого заключено то единственное совершенство, на которое может надеяться философ, - именно он в концентрированной форме сокрыт в переводе. Не существует музы философии, как нет и музы перевода.» (Комментарии 1997: 72). 
Это вневременное или «надисторическое» родство языков полагается достаточно очевидным лингвистическим допущением, а именно, в основе всех языков с тем или иным отклонением лежит одно и тоже означаемое. Перевод же, по мысли Беньямина, должен быть устремлен к тому, чтобы это универсальное означаемое было преобразовано в означающее, и это преобразование происходит не на уровне именования, но, скорее, как способ задавания значения. «Задача переводчика состоит в нахождении той интенции в отношении языка перевода, которая будит в нем эхо оригинала.... Перевод, вместо того чтобы добиваться смысловой схожести с оригиналом, должен любовно и скрупулезно создавать свою форму на родном языке в соответствии со способом производства значения оригинала, дабы оба они были узнаваемы как обломки некоего большего языка....

Настоящий перевод прозрачен, он не заслоняет собой оригинал, не закрывает ему свет, а наоборот, позволяет чистому языку, как бы усиленному его опосредованием, сообщать оригиналу свое сияние все более полно. Это достигается, прежде всего, благодаря

дословности в передаче синтаксиса: она доказывает, что именно слово, а не предложение есть первичный элемент переводчика.» (Комментарии 1997: 73).

Таким образом, перевод оказывается возможным постольку, поскольку языки несовершенны и всегда отстоят от истины. Сам перевод - это, исключительно, философское намерение, некое движение к истине, которая пребывает в своеобразной атопичности. Мы проходим через межъязыковые пространства, чтобы устремить наши языки к цельным и совершенным формам. Мы, вслед за Беньямином, приведем цитату Панвица, где достаточно ясно и выразительно определяется задача перевода: «Наши переводы, включая самые лучшие, исходят из неправильной посылки. Они хотят превратить хинди, греческий, английский в немецкий, вместо того, чтобы превращать немецкий в хинди, греческий, английский. Они гораздо больше благоговеют перед употреблением родного языка, чем перед духом иноязычных произведений... Принципиальная ошибка переводчика в том, что он фиксирует случайное состояние своего языка вместо того, чтобы позволить ему прийти в движение под мощным воздействием иностранного... Он обязан расширять и углублять свой язык посредством чужого. Мы совершенно не представляем, насколько это возможно, до какой степени язык способен преображаться.» (Комментарии 1997: 75).

\section{Часть четвертая.}

Перевод, бесспорно, располагается также в некотором семиотическом пространстве, где в основе своей исследуется феномен новизны. Семиотика как кодифицированное сообщение также выходит за рамки лингвистических аспектов перевода, сосредотачивая свое внимание на моменты искажения и трансформации оригинального сообщения в процессе перевода. Код - это особое внеязыковое присутствие смысла. Но передача смысла, на который нацелен семиотический перевод, есть всегда нечто непрерывно проблематическое, так как в этом случае смысл равен самому себе, внутри себя тождественен и устойчив. Вот почему логика всегда сторонится моментов новизны. Ю.М.Лотман указывает на несколько иную семиотическую ситуацию, когда семиозис осуществляется как креативная деятельность переводчика. Креативность отмечена моментом обратной непереводимости. То есть отношение перевода и оригинала не ограничивается смысловой связью, более того, перевод начинает активно избегать смысловой соотнесенности, утверждая собственную самостоятельность. «Самый факт возможности многократного художественного перевода одного и того же стихотворения различными переводчиками свидетельствует о том, что вместо точного соответствия тексту Т1 в этом случае сопоставлено некоторое пространство. Любой из заполняющих его текстов $\mathrm{T} 1, \mathrm{~T} 2, \mathrm{~T} 3$...Tn будет возможной интерпретацией, вместо симметричного преобразования асимметричное, вместо тождества элементов, составляющих Т1 и Т2, - условная их эквивалентность.... Возникающий в этих случаях текст мы будет рассматривать как новый, а создающий его акт перевода - как творческий.» (Лотман 1996: 15-16). В этом случае отношение между оригиналом и переводом приобретает достаточно нетрадиционное измерение, а именно, как отношение старины и новизны. Полагаю, что здесь недостаточны 
сложившиеся модернистские аллюзии, где новизна - это всегда преодоление и устранение старого, скорее всего, речь идет о существенном «приращении» «смысла» текста. «Поскольку смыслом в данном случае оказывается не только тот инвариантный остаток, который сохраняется при разнообразных трансформационных операциях, но и то, что при этом изменяется, мы можем констатировать приращение смысла текста в процессе их трансформаций» (Лотман 1996: 17).

Но что касается смысла, то любое приращение смысла неизбежно полагает совершенно иной смысл. Приращение смысла есть, одновременно, изменение смысла, так как смысл, по всей видимости, не может мыслиться количественно: сумма элементов смысла может характеризовывать объем понятия, тогда как отношения между этими элементами создают единственное качество смысла. В семиотических пространствах допускается как бы неизменность смыслового ядра при любых трансформациях, однако, ядро - это всего лишь один из возможных элементов смысла, а значит, перевод всегда сохраняет свое инобытие, несмотря на допустимое сходство, подобие, каузальный принцип связи между оригиналом и переводом.

\section{Заключение}

Как видим, оригинал и перевод формируются в качестве соотносимых инстанций тем различием, которое присутствует между ними. В зависимости от характера этого различия оригинал то утверждает свое превосходство, то устраняется от любой соотносимости или оценки. Это устранение происходит в тот момент, когда перевод начинает выступать в качестве самостоятельного объекта, формирует только ему свойственную среду, где оказывается возможным «знание» и «удовольствие», вдохновение и изменение, «производство» и преобразование. И странным образом, как только оригинал перестает соотноситься с переводом, то непременно сам становится переводом, взывая к некоторому абсолютному оригиналу. Можно будет сказать, что как только автор воспринимается как тот, кто предшествует тексту, то есть если мы утверждаем преимущество замысла над осуществлением, тогда оригинал учреждает иерархию интенциональностей, и в этом случае перевод соотносится с оригиналом не столько как текстом, сколько как с более насыщенной интенциональной средой. Если же автор совпадает, либо следует за текстом, рассматривая текст как опыт становления «знания» и «удовольствия», как опыт особого бытия мысли, то в этом случае место автора является также местом переводчика, но тогда переводчик как бы предшествует переводу, обладает некоторым избыточным свойством. В этом случае перевод и оригинал исходят из некоего единого места, где, словно сиамские близнецы, расположились автор и переводчик. Отношение оригинала и перевода формируется встречей автора и переводчика, и от характера этого отношения (дружба, вражда, зависть, любовь и т.д.) во многом зависит судьба произведения. Пожалуй, произведение - это то единственное, что делает возможным невозможное, - когда перевод становится оригиналом оригинала. 